\title{
The acceptability of repeat Internet-based hybrid diet assessment of previous 24-h dietary intake: administration of the Oxford WebQ in UK Biobank
}

\author{
Julieta Galante ${ }^{1}{ }^{*} \dagger$, Ligia Adamska ${ }^{2}$, Alan Young ${ }^{2}$, Heather Young ${ }^{3}$, Thomas J. Littlejohns ${ }^{2}$, \\ John Gallacher ${ }^{1}$ and Naomi Allen ${ }^{2}$ \\ ${ }^{1}$ Cochrane Institute of Primary Care and Public Health, Cardiff University, 5th Floor, Neuadd Meirionnydd, Heath Park, \\ Cardiff CF14 4YS, UK \\ ${ }^{2}$ Clinical Trial Service Unit and Epidemiological Studies Unit, Nuffield Department of Population Health, University of Oxford, \\ Richard Doll Building, Old Road Campus, Roosevelt Drive, Oxford OX3 7LF, UK \\ ${ }^{3}$ Cancer Epidemiology Unit, Nuffield Department of Population Health, University of Oxford, Richard Doll Building, Old Road \\ Campus, Roosevelt Drive, Oxford OX3 $7 L F$, UK
}

(Submitted 22 December 2014 - Final revision received 27 October 2015 - Accepted 2 November 2015 - First published online 11 December 2015)

\begin{abstract}
Although dietary intake over a single 24-h period may be atypical of an individual's habitual pattern, multiple 24-h dietary assessments can be representative of habitual intake and help in assessing seasonal variation. Web-based questionnaires are convenient for the participant and result in automatic data capture for study investigators. This study reports on the acceptability of repeated web-based administration of the Oxford WebQ - a 24-h recall of frequency from a set food list suitable for self-completion from which energy and nutrient values can be automatically generated. As part of the UK Biobank study, four invitations to complete the Oxford WebQ were sent by email over a 16-month period. Overall, 176012 (53\% of those invited) participants completed the online version of the Oxford WebQ at least once and $66 \%$ completed it more than once, although only $16 \%$ completed it on all four occasions. The response rate for any one round of invitations varied between 34 and $26 \%$. On most occasions, the Oxford WebQ was completed on the same day that they received the invitation, although this was less likely if sent on a weekend. Participants who completed the Oxford WebQ tended to be white, female, slightly older, less deprived and more educated, which is typical of health-conscious volunteer-based studies. These findings provide preliminary evidence to suggest that repeated 24-h dietary assessment via the Internet is acceptable to the public and a feasible strategy for large population-based studies.
\end{abstract}

Key words: Diet: Internet: Dietary assessment: Acceptability

The role of diet in a healthy lifestyle is widely acknowledged, but the contribution of specific nutrients and their impact on chronic disease remains unclear. This may, in part, be due to the inherent difficulties in accurately assessing dietary intake on a large scale.

Existing technologies do not enable comprehensive objective measurement of diet (e.g. recovery biomarkers) at a population level, and, although this may change, current dietary assessment methods are based on self-report (i.e. subjective) measures such as food diaries or FFQ. Each of these assessment methods has strengths and limitations. Food diaries, which require individuals to record everything they consume over a period of time, are burdensome to the participant ${ }^{(1)}$. FFQ, which ask for a limited number of habitual food intakes generally over a 1-year period, are easy to administer but lack specificity for many nutrients ${ }^{(2,3)}$. Food recall measures, in which participants are asked to report everything they consume, typically over a 24-h period, address many of these issues. Although dietary intake over a single $24-\mathrm{h}$ period may be atypical of an individual's habitual dietary pattern, assessment of multiple 24-h food recalls over a period of time can be representative of habitual intake and can help assess seasonal variation in dietary intake ${ }^{(4)}$.

Traditionally, paper-based questionnaires or computerassisted personal interviews have been used to assess dietary intake. More recently, there is growing awareness of the advantage of using web-based tools ${ }^{(5)}$. They are convenient and easy to use for the participant and result in automatic data capture for study investigators ${ }^{(4)}$. At present, research teams worldwide are developing web-based dietary assessment tools ${ }^{(6)}$. However, evidence regarding the performance of these tools is still limited. A recent review of innovative technologies for measuring diet in nutritional epidemiology concluded that more research is crucial to investigate the validity of innovative

* Corresponding author: J. Galante, email mjg231@cam.ac.uk

$\dagger$ Present address: Department of Psychiatry, University of Cambridge, Douglas House, 18b Trumpington Road, Cambridge CB2 8AH, UK. 
dietary assessment technologies ${ }^{(7)}$. If acceptable to the public, repeat 24-h recalls could provide a valid and convenient representation of habitual intake in large population studies.

The Oxford WebQ is a simple computerised 24-h dietary assessment tool suitable for self-completion using the Internet. The validity of the Oxford WebQ has been previously assessed in relation to an interviewer-administered $24-\mathrm{h}$ recall $^{(8)}$. This study reports preliminary evidence on the acceptability of repeated web-based administration of the Oxford WebQ over a 16-month period.

\section{Methods \\ Participants}

UK Biobank is a major national prospective cohort study designed to study a wide range of exposures related to lifestyle, environment and genes and their association with disease ${ }^{(9)}$. A non-representative sample of over 500000 UK volunteers aged 40-69 years, identified through National Health Service records, was recruited between 2006 and 2010. Participants attended assessment centres throughout the UK to undergo extensive baseline measurements, with collection of blood, urine and saliva samples ${ }^{(10)}$. Participants gave their written consent for follow-up through access to medical and other records for health-related research purposes.

\section{Diet assessment}

At recruitment, dietary intake was measured using a short selfcompleted FFQ different from the Oxford WebQ. This initial FFQ was designed to rank participants at baseline according to commonly eaten food groups, as well as seeking information about some common sources of various nutrients. However, it was recognised that this approach does not allow assessment of total energy intake or some specific nutrients. Therefore, this short FFQ was later supplemented by the administration of the Oxford WebQ to obtain more detailed nutrient-level information.

Similar to a 24-h dietary recall, the aim of the Oxford WebQ is to obtain information on the quantities of all foods and beverages consumed over the previous day. Unlike standard diet recall tools, however, the respondents are not asked to remember and report what they have consumed. Instead, akin to a FFQ, the Oxford WebQ presents individuals with twentyone food groups and requests them to indicate whether they consumed any of them over the previous day (e.g. Did you eat any bread or crackers yesterday?). A positive response to any of these questions results in the screen expanding to reveal a list of commonly consumed foods in the corresponding category. Respondents then need to select the amount of each food consumed using standard categories to indicate the amount consumed (e.g. two slices of bread), and for foods without a natural size (e.g. cheese) a portion size is specified as a 'serving' with a description of that particular serving size in the help section of the Oxford WebQ. Thus, the data collection approach used in the Oxford WebQ could be defined as a hybrid between a 24-h dietary recall and a FFQ.
Open-ended questions were generally avoided in the questionnaire so that replies could be coded automatically, although some free-text boxes are available for use when the options listed do not fit with what the participants have consumed. The Oxford WebQ also asks whether the previous 24-h period was a typical day or not and why and whether the participant routinely follows a special diet.

Overall, the Oxford WebQ contains over 200 individual food items. These items were chosen to encompass the major foods consumed in the UK, using information from population dietary surveys and pilot studies, and to address current hypotheses about certain foods and diseases ${ }^{(8)}$. The quantity of each food and beverage consumed during the previous $24 \mathrm{~h}$ is calculated by multiplying the assigned portion size of each food or beverage by the amount consumed. Energy and nutrient values of the reported food items are generated by multiplying the quantity of each food or drink consumed by its nutrient composition, as taken from McCance and Widdowson's The Composition of Foods and its supplements ${ }^{(11-21)}$. The majority of portion sizes were taken from Food Portion Sizes ${ }^{(22)}$.

The Oxford WebQ was developed by repeated testing until none or very few items had to be entered as free text by participants $^{(8)}$. As an initial evaluation study, 116 volunteers were asked to complete the Oxford WebQ immediately before completing a standard interviewer-administered 24-h recall and the results were compared. The mean differences in intake were less than $\pm 10 \%$ for all nutrients (e.g. $0 \cdot 1$ for energy, $-1 \cdot 3$ for protein, 4.6 for total fat, -3.4 for total sugars) except for carotene (-23.6) and vitamins $\mathrm{B}_{12}$ (43.5) and $\mathrm{D}$ (18.3). Completing the Oxford WebQ took a median of 12.5 min, whereas the 24 -h recall took $30 \mathrm{~min}$ to complete and $30 \mathrm{~min}$ to code.

\section{Procedure}

The Oxford WebQ was included at the assessment visit as part of the baseline measures for the last 70724 participants. It was also administered over the Internet to all UK Biobank participants with a known email address, who were invited to complete the Oxford WebQ on four separate occasions over a 16-month period.

For each of the four rounds, email invitations were sent on variable days of the week to the same person in order to capture changes in dietary intake between the working week and the weekend. Participants were encouraged to complete the questionnaire on the day of invitation, although they were allowed $3 \mathrm{~d}$ to complete the questionnaire for the first and second rounds of email invitations, after which time the link expired. This was extended to $14 \mathrm{~d}$ for the third and fourth rounds of email invitations to provide more time to complete the questionnaire, although the participants were still encouraged to complete it on the day of invitation. Participants did not receive incentives or reminders to complete the questionnaire.

Acceptability of the Oxford WebQ was assessed by rates of questionnaire completion. Statistical analyses were performed comparing age, sex, ethnic background, deprivation scores and education between Oxford WebQ responders and non-responders. Response rates by time of completion and 
number of occasions are shown. Finally, an overview of the respondents' estimated nutrient intake by sex is provided.

\section{Results}

A total of 211053 participants completed the Oxford WebQ, either at the recruitment assessment clinics or via the Internet. Oxford WebQ responses at the assessment clinics were excluded from the analyses presented below.

In total, 331013 participants (approximately $66 \%$ of the cohort) provided a valid email address and were invited to complete the Oxford WebQ online on four occasions between February 2011 and June 2012 (Fig. 1). Of the 331013 invited participants, 176012 (53\%) completed the online version of the Oxford WebQ at least once. Of the 176012 respondents, 115447 (66\%) completed the Oxford WebQ more than once. The response rate for any one round of invitations varied between 34 and $26 \%$, being significantly lower during the summer months $(P<0.001)$.

Compared with non-responders, participants who completed the online Oxford WebQ at any time were significantly more likely to be women, older, of white ethnic background, less deprived and more educated $(P$ for all $<0.001$ ). Participants who responded on multiple occasions were also more likely to be white, older and more educated than those who only completed it once (Table 1).

On most occasions, the Oxford WebQ was completed on the same day that they received the invitation (58\% overall for all rounds combined), although for later rounds the likelihood of same-day completion declined (Fig. 2). Among all, $78 \%$ of the participants completed the Oxford WebQ on the same day as the invitation if it was received on a weekday, compared with $23 \%$ if received at the weekend. Most participants completed the Oxford WebQ in the morning both on weekdays and weekends (Fig. 3).

An overview of the respondents' estimated nutrient intake by sex is provided in Table 2. For participants who completed the Oxford WebQ more than once, their mean nutrient intake was calculated. The median total energy intake for men was $9293.5 \mathrm{~kJ}$, of which an estimated $48.6 \%$ was carbohydrates, $32.2 \%$ was fats and $15.4 \%$ was protein. For women, the median total intake was $8030.4 \mathrm{~kJ}$, of which an estimated $49.6 \%$ was carbohydrates, $32.7 \%$ was fats and $16.2 \%$ was protein.

\section{Discussion}

This study found preliminary evidence that Internet-based administration of the Oxford WebQ is acceptable to the public. Overall, most participants ( $53 \%$ of those invited) completed the online version of the Oxford WebQ at least once, and most of them (66\% of the respondents) did so more than once.

However, only $16 \%$ completed the questionnaire four times, showing a rapid decay with increased repetition. Participant fatigue, even in highly motivated samples, needs to be taken into account when planning the number and density of dietary assessment repetitions. Increasing the gap between repeat measurements may help keep response rates high. Other timing

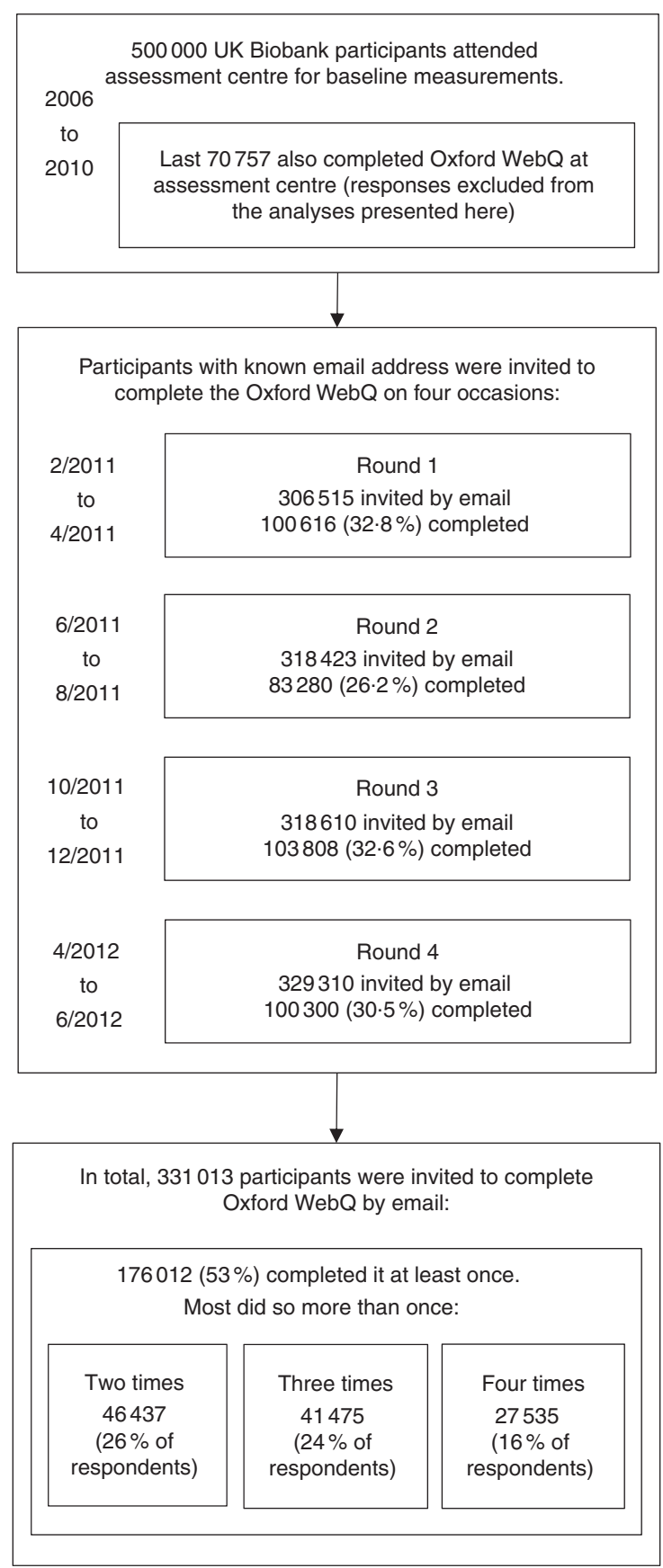

Fig. 1. Study flow chart and Oxford WebQ response rates. The number of participants invited by email varied according to the number of valid emails available on each round.

issues also affect rates: should it be necessary to collect dietary information during weekends or holiday periods, lower completion rates and increased delays are to be anticipated. Giving participants more time to complete the questionnaire reduced same-day completion rates and did not improve overall completion rates.

Compared with the rest of UK Biobank volunteers, those who completed the Oxford WebQ tended to be white, female, slightly older, less deprived and more educated, which is typical 
Table 1. Respondents' characteristics according to the number of times they have completed the Oxford WebQ (Numbers and percentages)

\begin{tabular}{|c|c|c|c|c|c|c|c|c|c|c|c|c|}
\hline \multirow[t]{2}{*}{ Number of times... } & \multicolumn{2}{|c|}{0 (non-responders) } & \multicolumn{2}{|c|}{1} & \multicolumn{2}{|c|}{2} & \multicolumn{2}{|l|}{3} & \multicolumn{2}{|c|}{4} & \multicolumn{2}{|c|}{ Total } \\
\hline & $n$ & $\%$ & $n$ & $\%$ & $n$ & $\%$ & $n$ & $\%$ & $n$ & $\%$ & $n$ & $\%$ \\
\hline \multicolumn{13}{|l|}{ Sex } \\
\hline Females & 80060 & 52 & 32925 & 54 & 25824 & 56 & 23305 & 56 & 15303 & 56 & 177417 & 54 \\
\hline Males & 74941 & 48 & 27640 & 46 & 20613 & 44 & 18170 & 44 & 12232 & 44 & 153596 & 46 \\
\hline \multicolumn{13}{|l|}{ Age in $2011^{\star}$ (years) } \\
\hline$<49$ & 29771 & 19 & 10710 & 18 & 7826 & 17 & 6353 & 15 & 3765 & 14 & 58425 & 18 \\
\hline $50-59$ & 50204 & 32 & 19674 & 32 & 15218 & 33 & 13282 & 32 & 8639 & 31 & 107017 & 32 \\
\hline $60-69$ & 63127 & 41 & 25723 & 42 & 20133 & 43 & 19025 & 46 & 13183 & 48 & 141191 & 43 \\
\hline Over 70 & 11899 & 8 & 4458 & 7 & 3260 & 7 & 2815 & 7 & 1948 & 7 & 24380 & 7 \\
\hline \multicolumn{13}{|l|}{ Ethnicity* } \\
\hline White & 143974 & 93 & 57638 & 95 & 44744 & 96 & 40140 & 97 & 26835 & 97 & 313331 & 95 \\
\hline Other & 10261 & 7 & 2734 & 5 & 1546 & 3 & 1184 & 3 & 602 & 2 & 16327 & 5 \\
\hline Unknown & 766 & 0 & 193 & 0 & 147 & 0 & 151 & 0 & 98 & 0 & 1355 & 0 \\
\hline \multicolumn{13}{|l|}{ Deprivation score* } \\
\hline 1 (least deprived) & 32830 & 21 & 13590 & 22 & 10373 & 22 & 9259 & 22 & 6092 & 22 & 72144 & 22 \\
\hline 2 & 32180 & 21 & 13154 & 22 & 9904 & 21 & 8902 & 21 & 5789 & 21 & 69929 & 21 \\
\hline 3 & 31759 & 20 & 12254 & 20 & 9610 & 21 & 8272 & 20 & 5780 & 21 & 67675 & 20 \\
\hline 4 & 30902 & 20 & 11864 & 20 & 9220 & 20 & 8317 & 20 & 5489 & 20 & 65792 & 20 \\
\hline 5 (most deprived) & 27330 & 18 & 9703 & 16 & 7330 & 16 & 6725 & 16 & 4385 & 16 & 55473 & 17 \\
\hline \multicolumn{13}{|l|}{ Education* } \\
\hline College or university degree & 62103 & 40 & 28374 & 47 & 23540 & 51 & 21726 & 52 & 14585 & 53 & 150328 & 45 \\
\hline NVQ or HND or HNC or equivalent & 24264 & 16 & 8516 & 14 & 6059 & 13 & 5105 & 12 & 3200 & 12 & 47144 & 14 \\
\hline A levels/AS levels or equivalent & 4892 & 3 & 2060 & 3 & 1613 & 3 & 1430 & 3 & 982 & 4 & 10977 & 3 \\
\hline O levels/GCSEs or equivalent & 41845 & 27 & 15908 & 26 & 11835 & 25 & 10533 & 25 & 7003 & 25 & 87124 & 26 \\
\hline None of the above & 20093 & 13 & 5395 & 9 & 3228 & 7 & 2556 & 6 & 1695 & 6 & 32967 & 10 \\
\hline Unknown & 1804 & 1 & 312 & 1 & 162 & 0 & 125 & 0 & 70 & 0 & 2473 & 1 \\
\hline
\end{tabular}

NVQ, National Vocational Qualification; HND, Higher National Diploma; HNC, Higher National Certificate; AS, Advanced Subsidiary; GCSE, General Certificate of Secondary Education. ${ }^{*} P$ for difference between responders and non-responders $<0.001$ (demographic characteristics were compared between respondents and non-respondents using $\chi^{2}$ tests).



Fig. 2. Number of participants who completed the Oxford WebQ by day of response for each round. * Date data is missing for thirty-three participants. $\square$, Same day; $\square$, next day; $\square$, later.

of health-conscious volunteer-based studies. At the same time, UK Biobank participants are a non-representative sample: on average less deprived, better educated and under-represented in unskilled occupations than the national population ${ }^{(23)}$. This makes this Oxford WebQ sample highly selected, and therefore not suitable for analyses that require samples to be representative. However, the sample still shows sufficiently large numbers of participants with different levels of potential risk factors, allowing for generalisable associations between baseline characteristics and subsequent health outcomes to be made ${ }^{(10,24)}$.

A comparison of our respondents' estimated nutrient intake with the National Diet and Nutrition Survey ${ }^{(25)}$ shows that values are within the expected normal range except for energy

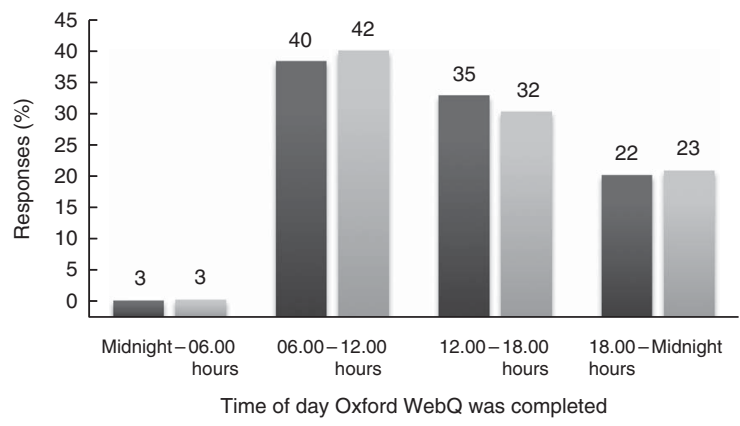

Fig. 3. Time of day the Oxford WebQ was completed on weekdays and weekend days. Date data is missing for thirty-three participants. $\square$, Weekend; $\square$, weekday.

intake (specifically from carbohydrate and SFA), which is somewhat higher in UK Biobank participants compared with national age- and sex-matched survey data. This might be reflecting the different data collection methods and/or the unrepresentative nature of the UK Biobank cohort.

Studies in various areas of health research have shown that traditional epidemiological risk factors can be collected with equal or even better reliability over the Internet compared with traditional approaches ${ }^{(26)}$. Response rates to web questionnaires have been found to be comparable with paper-based versions, at least in settings where the population generally has good access to the Internet ${ }^{(27,28)}$. Although participants with higher socio-economic indicators were more likely to respond, these trends were small (with highly significant $P$ values 
Table 2. Respondents' estimated nutrient intake based on 24-h dietary recall according to responses from the Oxford WebQ (Medians and interquartile ranges)

\begin{tabular}{|c|c|c|c|c|}
\hline \multirow[b]{2}{*}{ Nutrients } & \multicolumn{2}{|c|}{ Men } & \multicolumn{2}{|c|}{ Women } \\
\hline & Median & Interquartile range & Median & Interquartile range \\
\hline Total energy intake (kJ) & 9293.0 & $7792 \cdot 8-11002 \cdot 5$ & $8030 \cdot 1$ & $6763 \cdot 1-9442 \cdot 1$ \\
\hline Carbohydrates (\% energy) & 48.6 & $43 \cdot 0-54 \cdot 0$ & $49 \cdot 6$ & $44 \cdot 2-54 \cdot 7$ \\
\hline Starch $(g)$ & 131.9 & $103 \cdot 4-162 \cdot 0$ & $109 \cdot 4$ & $84.9-135.4$ \\
\hline Total sugars $(\mathrm{g})$ & 118.9 & $90 \cdot 7-151 \cdot 8$ & $110 \cdot 2$ & $84 \cdot 8-139 \cdot 9$ \\
\hline Fats (\% energy) & $32 \cdot 2$ & $27 \cdot 9-36 \cdot 4$ & $32 \cdot 7$ & $28 \cdot 3-36 \cdot 9$ \\
\hline PUFA (\% energy) & $5 \cdot 6$ & $4 \cdot 3-7 \cdot 1$ & $5 \cdot 8$ & $4 \cdot 4-7.4$ \\
\hline SFA (\% energy) & $12 \cdot 3$ & $10 \cdot 1-14 \cdot 5$ & $12 \cdot 4$ & $10 \cdot 3-14 \cdot 6$ \\
\hline Protein (\% energy) & $15 \cdot 4$ & $13 \cdot 5-17 \cdot 6$ & $16 \cdot 2$ & $14 \cdot 1-18 \cdot 5$ \\
\hline Alcohol (\% energy) & 4.5 & $0-10 \cdot 2$ & $2 \cdot 3$ & $0-6 \cdot 8$ \\
\hline $\mathrm{Ca}(\mathrm{mg})$ & 964.2 & $764 \cdot 5-1200 \cdot 0$ & 905.6 & $718 \cdot 4-1122 \cdot 4$ \\
\hline Carotene $(\mu \mathrm{g})$ & $2302 \cdot 1$ & $1128 \cdot 4-3900 \cdot 9$ & $2760 \cdot 0$ & $1479 \cdot 3-4459 \cdot 2$ \\
\hline Englyst dietary fibre $(\mathrm{g})$ & $15 \cdot 9$ & $12 \cdot 2-20 \cdot 3$ & $15 \cdot 5$ & $12 \cdot 0-19 \cdot 5$ \\
\hline Folate $(\mu \mathrm{g})$ & $302 \cdot 1$ & $240 \cdot 8-375 \cdot 2$ & 277.9 & $221 \cdot 2-345 \cdot 3$ \\
\hline $\mathrm{Fe}(\mathrm{mg})$ & $14 \cdot 2$ & $11 \cdot 5-17 \cdot 1$ & $12 \cdot 7$ & $10 \cdot 4-15 \cdot 3$ \\
\hline $\mathrm{Mg}(\mathrm{mg})$ & $356 \cdot 1$ & $295 \cdot 2-425 \cdot 6$ & 323.9 & $269 \cdot 2-384 \cdot 5$ \\
\hline $\mathrm{K}(\mathrm{mg})$ & $3747 \cdot 7$ & $3090 \cdot 8-4486 \cdot 9$ & $3555 \cdot 6$ & $2937 \cdot 5-4247 \cdot 0$ \\
\hline Retinol $(\mu \mathrm{g})$ & $309 \cdot 7$ & $200 \cdot 2-437 \cdot 0$ & $282 \cdot 0$ & $186 \cdot 9-397 \cdot 1$ \\
\hline Vitamin $B_{12}(\mu \mathrm{g})$ & $5 \cdot 6$ & $3 \cdot 8-8 \cdot 4$ & 5.4 & $3 \cdot 5-8 \cdot 1$ \\
\hline Vitamin $B_{6}(\mathrm{mg})$ & $2 \cdot 2$ & $1 \cdot 8-2 \cdot 7$ & $2 \cdot 0$ & $1 \cdot 6-2 \cdot 5$ \\
\hline Vitamin $C(\mathrm{mg})$ & $126 \cdot 9$ & $76 \cdot 7-191 \cdot 7$ & $135 \cdot 2$ & $85 \cdot 6-200 \cdot 6$ \\
\hline Vitamin D $(\mu \mathrm{g})$ & $2 \cdot 2$ & $1 \cdot 3-3 \cdot 8$ & $2 \cdot 0$ & $1 \cdot 1-3 \cdot 6$ \\
\hline Vitamin E (mg) & 8.5 & $6 \cdot 2-11 \cdot 4$ & 8.7 & $6 \cdot 5-11 \cdot 4$ \\
\hline
\end{tabular}

reflecting the large sample size) and may be more dependent on patterns of use rather than on Internet access ${ }^{(29)}$.

Internet-based studies bear some advantages over their offline equivalents. The investment that is required for an online study tends to be lower, mostly due to low marginal costs ${ }^{(28)}$ and Internet-based recruitment greatly increases geographic and demographic reach ${ }^{(30)}$. Moreover, owing to computerised display methods and automated data capture techniques, Internet-based studies avoid the errors associated with manual entry or optical scanning data entry techniques. Finally, the lack of face-to-face contact makes some people feel more comfortable to participate in Internet-based studies and respond more honestly $^{(26,31)}$.

Both the validity of the Oxford WebQ for obtaining energy and nutrient values and its acceptability among members of the public for repeated remote testing need to be confirmed in future studies. However, preliminary evidence indicates that the Oxford WebQ may be a powerful tool for dietary assessment in large population-based studies.

\section{Acknowledgements}

The authors acknowledge all the UK Biobank staff and the half-a-million UK Biobank participants who joined the study.

This research received no specific grant from any funding agency, commercial or not-for-profit sectors.

J. G. analysed the data and wrote the article; L. A. analysed the data and wrote the article; A. Y. collected the data; H. Y. processed the data; J. G. designed the study and wrote the article; T. J. L. analysed the data and wrote the article; N. A. formulated the research questions, designed the study, carried it out, analysed the data and wrote the article.

The authors declare that there are no conflicts of interest.

\section{References}

1. Thompson FE \& Byers $\mathrm{T}$ (1994) Dietary assessment resource manual. J Nutr 124, 2245s-2317s.

2. Bingham SA, Luben R, Welch A, et al. (2003) Are imprecise methods obscuring a relation between fat and breast cancer? Lancet 362, 212-214.

3. Prentice RL, Mossavar-Rahmani Y, Huang Y, et al. (2011) Evaluation and comparison of food records, recalls, and frequencies for energy and protein assessment by using recovery biomarkers. Am J Epidemiol 174, 591-603.

4. Schatzkin A, Subar AF, Moore S, et al. (2009) Observational epidemiologic studies of nutrition and cancer: the next generation (with better observation). Cancer Epidemiol Biomarkers Prev 18, 1026-1032.

5. Boeing H (2013) Nutritional epidemiology: new perspectives for understanding the diet-disease relationship? Eur J Clin Nutr 67, 424-429.

6. Boeing H \& Margetts BM (2014) Nutritional epidemiology. In Handbook of Epidemiology, 2nd ed., pp. 1659-1703 [W Ahrens and I Pigeot, editors]. New York, NY: Springer Science + Business Media.

7. Illner AK, Freisling H, Boeing H, et al. (2012) Review and evaluation of innovative technologies for measuring diet in nutritional epidemiology. Int $J$ Epidemiol $\mathbf{4 1}$, $1187-1203$.

8. Liu B, Young H, Crowe FL, et al. (2011) Development and evaluation of the Oxford WebQ, a low-cost, web-based method for assessment of previous $24 \mathrm{~h}$ dietary intakes in large-scale prospective studies. Public Health Nutr 14, 1998-2005.

9. Collins R (2012) What makes UK Biobank special? Lancet 6736, 60404-60408.

10. Allen N, Sudlow C, Downey P, et al. (2012) UK Biobank: current status and what it means for epidemiology. Health Policy Technol 1, 123-126.

11. Holland B, Welch A \& Unwin I (1991) McCance and Widdowson's the Composition of Food, 5th ed. Cambridge: Royal Society of Chemistry. 
12. Food Standards Agency (2002) McCance and Widdowson's the Composition of Foods, 6th ed. Cambridge: Royal Society of Chemistry.

13. Holland B, Unwin I \& Buss D (1988) Cereals and Cereal Products. Third Supplement to McCance and Widdowson's the Composition of Foods, 4th ed. Cambridge: Royal Society of Chemistry.

14. Holland B, Brown J \& Buss D (1993) Fish and Fish Products. Third Supplement to McCance and Widdowson's the Composition of Food, 5th ed. Cambridge: Royal Society of Chemistry.

15. Holland B, Unwin I \& Buss D (1988) Fruit and Nuts. First Supplement to McCance and Widdowson's the Composition of Foods, 5th ed. Cambridge: Royal Society of Chemistry.

16. Chan W, Brown J \& Lee S (1995) Meat, Poultry and Game. Fifth Supplement to McCance and Widdowson's the Composition of Foods, 5th ed. Cambridge: Royal Society of Chemistry.

17. Chan W, Brown J \& Church S (1996) Meat Products and Dishes. Sixth Supplement to McCance and Widdowson's the Composition of Foods, 5th ed. Cambridge: Royal Society of Chemistry.

18. Holland B, Unwin I \& Buss D (1989) Milk Products and Eggs. Fourth Supplement to McCance and Widdowson's the Composition of Foods, 4th ed. Cambridge: Royal Society of Chemistry.

19. Chan W, Brown J \& Buss D (1994) Miscellaneous Foods. Fourth Supplement to McCance and Widdowson's the Composition of Foods, 5th ed. Cambridge: Royal Society of Chemistry.

20. Holland B, Welch A \& Buss D (1992) Vegetable Dishes. Second Supplement to McCance and Widdowson's the Composition of Foods, 5th ed. Cambridge: Royal Society of Chemistry.

21. Holland B, Unwin I \& Buss D (1991) Vegetables, Herbs and Spices. Fifth Supplement to McCance and Widdowson's the Composition of Foods, 5th ed. Cambridge: Royal Society of Chemistry.
22. Ministry of Agriculture FaF (1993) Food Portion Sizes, 2nd ed. London: HMSO.

23. Hutchings S, Ayres J, Cullinan P, et al. (2014) Using the UK Biobank study to estimate occupational causes of chronic disease: comparability with the UK national population and adjustment for bias. Occup Environ Med 71, Suppl. 1, A79.

24. Rothman KJ, Gallacher JE \& Hatch EE (2013) Why representativeness should be avoided. Int $J$ Epidemiol $\mathbf{4 2}$, 1012-1014

25. Public Health England and Food Standards Agency (2014) National Diet and Nutrition Survey. Results from Years 1 to 4 (combined) of the rolling programme for 2008 and 2009 to 2011 and 2012 - Appendices and tables - Chapter 8. https://www. gov.uk/government/statistics/national-diet-and-nutrition-surveyresults-from-years-1-to-4-combined-of-the-rolling-programmefor-2008-and-2009-to-2011-and-2012 (accessed October 2015).

26. van Gelder MM, Bretveld RW \& Roeleveld N (2010) Web-based questionnaires: the future in epidemiology? Am J Epidemiol 172, 1292-1298.

27. Balter K, Balter O, Fondell E, et al. (2005) Web-based and mailed questionnaires: a comparison of response rates and compliance. Epidemiology 16, 577-579.

28. Oppenheimer AJ, Pannucci CJ, Kasten SJ, et al. (2011) Survey says? A primer on web-based survey design and distribution. Plastic Reconstr Surg 128, 299-304.

29. White P \& Selwyn N (2011) Moving online? An analysis of patterns of adult Internet use in the UK, 2002-2010. Inf Commun Soc 16, 1-27.

30. Miller PG \& Sonderlund AL (2010) Using the Internet to research hidden populations of illicit drug users: a review. Addiction 105, 1557-1567.

31. Mathieu E, Barratt A, Carter SM, et al. (2012) Internet trials: participant experiences and perspectives. BMC Med Res Methodol 12, 162. 